Artículo de Investigación

\title{
Mecanismos de financiación y gestión de recursos financieros del sector agropecuario en Colombia*
}

\section{Mechanisms of financing and management of financial resources in the agricultural sector in Colombia}

Jahir Alexander Gutiérrez Ossa** Nelson Eduardo Castaño Giraldo** Elimeleth Asprilla Mosquera****

Fecha de recepción: 12 de agosto de 2013

Concepto de evaluación: 11 de febrero de 2014

Fecha de aprobación: 21 de marzo de 2014

* Este artículo es producto del proyecto de investigación "Canales y mecanismos de acceso a la financiación y fondeo préstamos a sectores no aptos para el sistema financiero colombiano. El caso del sector agrícola, construcción, exportadores, municipios y pymes", realizado por el Grupo de Investigación Observatorio Público de la Institución Universitaria Tecnológico de Antioquia.

** Economista de la Universidad de Medellín, Colombia. PhD en Administración Pública, Atlantic International University (AIU), Honolulú, USA. Magíster en Desarrollo, Universidad Pontificia Bolivariana, Medellín, Colombia. Miembro del grupo de investigacion Observatorio Público del Tecnológico de Antioquia. Correo electrónico: jagutier@tdea.edu.co

*** Matemático de la Universidad de Antioquia, Medellín, Colombia. Maestría en Matemáticas Aplicadas de la Universidad EAFIT de Medellín. Coordinador del Programa académico Tecnología en Gestión Financiera del Tecnológico de Antioquia. Miembro del grupo de investigacion Observatorio Publico del Tecnologico de Antioquia. Correo electrónico: ncastano70@gmail.com

${ }^{* * * *}$ Economista de la Universidad Simón Bolívar, Barranquilla. Especialista en Gestión Pública de la Escuela Superior de Administración Pública ESAP, Antioquia-Chocó, Quibdó. Especialista en Gerencia de las Organizaciones, Corporación Universitaria Adventista -UNAC- Medellín. Candidato a Maestría en Administración con énfasis en Mercadotecnia Universidad Montemorelos de México. Miembro del grupo de investigacion Observatorio Público del Tecnologico de Antioquia. Decano Facultad de Administración. Correo electrónico: eliasmo@tdea.edu.co 
Mecanismos de financiación y gestión de recursos financieros del sector agropecuario Jahir A. Gutiérrez O. - Nelson E. Castaño - Elimeleth Asprilla M.

\section{Resumen}

En el artículo se observa el impacto que tiene la oferta bancaria y crediticia, frente a las necesidades de recursos para inversión del sector agropecuario en Colombia. La disposición de recursos financieros aptos para el sector agropecuario, constituye uno de sus principales cuellos de botella. Los análisis exploratorio y descriptivo fungen como fundamento metodológico para el desarrollo temático del escrito. La necesidad de liquidez e irrigación de recursos son tomados como puntos de quiebre para el sector, y, a la vez, como no se conoce claramente el impacto del sector financiero frente a las necesidades de crédito, se deja la viabilidad del mismo a las condiciones cíclicas del mercado. Así, la apertura financiera al sector agropecuario debe ser una constante en la banca.

Palabras clave: fluctuaciones económicas, mercados financieros, productividad del capital y del total de factores, riesgo moral y selección adversa.

JEL: E32, E44, D24, D81

\section{Abstract}

The article notes the impact that has banking and credit versus the needs of resource for investment of the agricultural sector in Colombia. The provision of financial resources for the agricultural sector is one of the main bottlenecks. The exploratory and descriptive analyses serve as a methodological basis for the thematic development of this paper. The need for liquidity and irrigation of resources are taken as break points for the industry, and, at the same time, as the impact of the financial sector versus credit needs is not clearly known, it has been left its viability to the cyclical market conditions. Thus, the financial opening to the agricultural sector should be a constant in banking.

Keywords:economic fluctuations, financial markets, productivity of capital and the total number of factors, moral hazard and adverse selection. 


\section{INTRODUCCIÓN}

El sistema bancario colombiano ha dejado impronta respecto a la restricción que tiene frente a la posibilidad de focalizar recursos del crédito para la financiación del sector agropecuario. Más allá de esta discrecionalidad, es importante establecer qué condiciones presenta el sector para ser considerado no apto, así mismo, determinar las fuentes de recursos sobre las que este ha terminado solventando sus necesidades financieras, e identificar finalmente, si este no cuenta con los elementos suficientes para ser sujeto activo de la banca, quedando a expensas del apoyo crediticio y financiero del Estado.

La actividad agropecuaria constituye un rubro importante para la generación de recursos alimentarios y productivos del país, y, a su vez, de empleo y de flujo de dinero. No obstante, la correspondencia con sectores de la banca ha obedecido más a la disposición encabezada por el Estado, en cuanto al otorgamiento de recursos, entre otras, por la aversión constante de la banca privada a solventar dicho requerimiento, $y$, en otros casos, por el interés del gobierno nacional de procurar en cualquiera de los casos que la producción agropecuaria del país no se vea en riesgo por limites crediticios o financieros.

El papel que ha jugado la banca crediticia y financiera, particularmente privada, ha terminado por enfatizar y reiterar que las condiciones estructurales que presenta el sector agropecuario lo pone al margen de las prioridades que tiene la banca para abrir fuentes o líneas de crédito para dicho sector. Este hecho insta precisamente para establecer de manera formal y técnica, además de los institucionales, los 
argumentos que tiene la banca para hacerse a un lado de la actividad agropecuaria, señalándola como sector no atractivo para el crédito; aseveración que puede traerle más dificultades, que la negación financiera.

El poder evaluar las condiciones crediticias y financieras de la banca representa la oportunidad para ubicar al sector en diferentes niveles de la cadena de valor a la cual está expuesta. Por encima de las aprehensiones de uno y otro lado, la trascendencia del análisis se destaca a la hora de poder definir claramente las perspectivas que tiene el sector en la materia, pero, igualmente, las oportunidades ciertas que podría traer para la propia banca privada el sacar a este sector de la lista de sectores no aptos del crédito, proponiendo alternativas para los intereses del sector.

La puesta en el análisis de la selección adversa como marco transversal metodológico, sirve de fundamento para orientar los argumentos técnicos que terminan por auspiciar o desdeñar las posibilidades de generación de crédito y financiación del sector agropecuario. A su vez, el riesgo moral representa la base para estimar a ciencia cierta los limites y restricciones que la banca objeta para no hacer parte del grupo de estamentos que irrigan recursos hacia el sector, evaluando, asimismo, que tanto su posición discrecional puede terminar empeorando la situación de este último, como también la de la banca.
En cuanto a la estructura de análisis del artículo, conforme a los elementos planteados, esta obedece a la siguiente definición: en primer lugar, de la revisión sobre las condiciones económicas y financieras del sector agropecuario para ser sujetos de crédito. En segundo lugar, de la importancia y relevancia sobre la cual estima el sistema bancario, crediticio $\mathrm{y}$ financiero al sector, y en tercer lugar, el ajuste y definición de elementos y parámetros con los cuales establecer las calidades y condiciones del sector agropecuario para ser estimado sujeto de crédito apto para la banca privada y pública colombiana.

\section{ESTRUCTURA ECONÓMICA, FINANCIERA Y PRODUCTIVA DEL SECTOR AGROPECUARIO EN COLOMBIA}

La actividad económica en el campo comprende una serie de aparejos que no solo están sujetos a la disponibilidad y productividad del suelo frente al tipo de bien o producto agropecuario en explotación. La condición cíclica que caracteriza todos los niveles de actividad, representa el marco de trabajo que esquematiza las probabilidades de acceso que puede tener el sector en los diferentes mercados de los cuales depende directamente su actividad, pero asimismo, de la ascendencia y reciprocidad que pueda tener en otros frentes, entre los que se cuenta la estructura de apoyo, financiación y fondeo del sector. Banagrario (2006, p. 46) expone: 
Colombia es un país que a diferencia de los demás países de la región, ha hecho esfuerzos importantes a partir de la década de 1990 por elaborar una política pública dirigida al financiamiento del sector agropecuario. Para ello creó un marco normativo (ley 16 de 1990) que establece el Sistema Nacional de Crédito Agropecuario (SNCA), cuya labor es coordinar, elaborar y definir dicha política sectorial bajo la administración de la Comisión Nacional de Crédito Agrario (CNCA). Además, se creó el Fondo para el Financiamiento del Sector Agropecuario de Colombia - Finagro (un banco público de segundo piso con orientación sectorial) y el Fondo Agropecuario de Garantías (FAG), y para completar este esquema de financiamiento, en 1999 se dio paso a un banco de primer piso especializado en el sector agropecuario, el Banco Agrario de Colombia (Banagrario). Es decir, el sector público colombiano tiene un sistema de financiamiento al sector agropecuario cuya cara final es Banagrario.

El sector ha dependido del consumo directo de las familias y de las empresas agroindustriales, que conforme las necesidades y demandas, reportan a través del mercado los productos requeridos en las etapas propias de cosecha y producción, que terminan siendo igualmente cíclicas. Al paso de las alteraciones que puedan acontecer en el proceso de recolección, entrega y procesamiento de los productos generados en el campo con carácter productivo, la multiplicidad de criterios que rodean al sector multiplica el esfuerzo para que este sea rentable al movimiento de los ciclos hasta los mercados. La Nota Económica (2012, p. 24) señala:

La agricultura es vital para el desarrollo de las personas y, por tanto, de las economías. En Colombia el sector agrícola representó $6,24 \%$ del producto interno bruto (PIB) en el primer trimestre de 2012, y aportó $16,9 \%$ de la fuerza laboral del país, siendo la tercera actividad en ofrecer empleo a la población económicamente activa (PEA), según las cifras del Dane para el mes de junio de 2012. A pesar de su importancia, esta actividad nacional presenta una gran brecha frente a otros países en términos de competitividad, puesto que al ser intensiva en mano de obra y no estar tecnificada, presenta elevados costos que impiden impulsar el crecimiento de la industria y obtener una mayor participación en el mercado. Por el contrario, el sector agrícola se encuentra ahora amenazado por la llegada de productos importados más baratos que los nacionales. Esto es el resultado de los atrasos en la cadena productiva que presenta la agricultura colombiana. 
La optimización en la producción agropecuaria corre por cuenta de parámetros que están por fuera incluso del ciclo económico y productivo que, para el efecto, debe asumir el sector. En este sentido, independiente del margen esperado, toda producción realizada extiende o reporta unas expectativas de rentabilidad, que se traducen en el aliciente o detonante para que sea contemplado como un músculo además de productivo, con la capacidad suficiente para atraer recursos de inversión o de crédito para que los elementos que no alcanzan a ser parte de las condiciones de la propia producción sean apalancados por ello. Analiza Gutiérrez (2004, p.15):

Las áreas rurales y el sector agrícola enfrentan situaciones que han sido ampliamente debatidas en la literatura: los mayores costos de transacción derivados de la distancia, el riesgo propio de las actividades agropecuarias, la ausencia de garantías para los préstamos por la pobreza prevaleciente en la población rural, así como de los costos de obtener información crediticia confiable acerca de los deudores rurales. Al hablar de desarrollo productivo en el sector rural interesa destacar que el microcrédito tiene consecuencias benéficas sobre la reducción de la pobreza. El mecanismo de operación es que el microcrédito rural permite aumentar las oportunidades de mercado y productivas de los agricultores y de las actividades rurales, con lo cual los ocupados en los sectores rurales pueden mejorar su productividad y, por ende, sus ingresos y de esta manera reducir sus niveles de pobreza.

Es posible que gran parte de la animadversión sobre las condiciones de acceso de financiación del sector agropecuario estén ancladas en el desconocimiento que se tiene de manera profunda de lo que implica allanar recursos para un sector que está más expuesto a los vaivenes de los mercados y de las condiciones climáticas que otros en particular; hecho que, a la postre, indica que aún la predisposición del crédito no depende de la vulnerabilidad manifiesta de un sector, sino de la incapacidad para comprender que la mecánica que corre por este es distinta a la que se estima de manera general. Reitera Gutiérrez (2004, p. 15):

Del mismo modo, se desea establecer que las actividades agrícolas si bien son un componente esencial de la actividad y los ingresos rurales, son parte y no el total de los ingresos rurales. De manera creciente hay fuentes adicionales de ingreso en el sector rural en el comercio, en el turismo rural, en pequeñas manufacturas, en el empleo estacional urbano, lo cual hace que el acceso a financiamiento no es solamente una cuestión de desarrollo productivo agrícola, sino también de actividades complementarias. 
Es necesario identificar el escenario económico crediticio, económico y financiero sobre el cual gira el entorno de la actividad productiva del sector agropecuario. Si bien, su estructura cíclica ofrece algunos elementos de análisis, la realidad es que el ciclo completo solamente representa una fuente de información y no la explicación completa. Para poder profundizar en ello, es relevante que puedan ser estimados los parámetros convergentes $\mathrm{y}$ divergentes que explican la conducta económica, financiera y productiva del sector agropecuario de manera complementaria y dispar, para con ello, poder compilar los fundamentos que proveen argumentos concretos. Anota Proexport (2010, p. 5):

El sector aporta el $9 \%$ del PIB, sus ventas al exterior representan el $21 \%$ del valor de las exportaciones totales y genera el $19 \%$ del empleo a nivel nacional y el $66 \%$ en las zonas rurales. De los 10 principales productos no tradicionales de exportación, 7 pertenecen al sector. Para el periodo 2004-2009 el PIB sectorial creció $2.3 \%$ promedio real anual, alcanzando niveles de $3.9 \%$ en los años 2006 y 2007. El comportamiento favorable se explica, no sólo por el incremento de las ventas externas agrícolas (de US\$3 mil millones en 2004 a US\$6 mil millones en 2009), sino por la ampliación del mercado interno.
La pérdida de importancia del sector agropecuario, al pasar de ser el primero al tercero, con respecto a la participación del producto interno bruto, no puede explicarse simplemente por el incremento e interés en las actividades secundarias y terciarias, ni tampoco, por el impacto de los mercados financieros internacionales, cuando en términos reales el sector ha perdido trascendencia. La escasa evaluación compleja y estructural de lo que implica el reacomodamiento de un sector, permite que surtan aseveraciones con poco atino y contundencia a la hora de explicar el desempeño económico de un sector tan relevante. De nuevo contextualiza Proexport (2010, p. 6):

Colombia, uno de los países con mayor potencial de expansión de tierras para uso agrícola en el mundo. Según la FAO, Colombia se ubica en el puesto 25 entre 223 países en donde se evalúa el potencial de expansión del área agrícola sin afectar el área de bosque natural. Este potencial de crecimiento según el Ministerio de Agricultura y Desarrollo Rural se estima en 10 millones de hectáreas, dentro de las que se encuentran áreas no aprovechadas y otras que tradicionalmente han sido utilizadas sin atender criterios de vocación productiva.

Del sector agropecuario, en tanto producción agrícola y ganadera, en 
ningún documento de trascendencia se plasma la pérdida de relevancia o reemplazo por otro sector, puesto que esto, entre otras cosas, significaría que el consumo humano habría dejado de crecer o que las demandas por recursos de origen agropecuario estarían al margen de la producción agroindustrial en el mundo, nada más alejado de la realidad. La presión por los recursos del suelo es tal, que a ciencia cierta se trata de establecer las necesidades alimentarias y de producción del ser humano. (Ver Tabla 1)

Tabla 1. Potencial tierras agrícolas en el mundo 2008, millones de hectáreas.

\begin{tabular}{|c|c|c|c|c|}
\hline Ranking & País & $\begin{array}{c}\text { Superficie } \\
\text { Total }\end{array}$ & $\begin{array}{c}\text { Superficie } \\
\text { agrícola (*) }\end{array}$ & $\begin{array}{c}\text { Potencial } \\
\text { agrícola (**) }\end{array}$ \\
\hline 1 & China & 969 & 562 & 165 \\
2 & Australia & 774 & 425 & 127 \\
3 & Estados Unidos & 963 & 411 & 123 \\
4 & Brasil & 851 & 263 & 79 \\
5 & Rusia & 1709 & 215 & 64 \\
6 & Kazajistán & 272 & 207 & 62 \\
7 & India & 328 & 179 & 53 \\
8 & Arabia Saudita & 214 & 173 & 52 \\
9 & Sudán & 251 & 136 & 41 \\
10 & Argentina & 278 & 133 & 40 \\
22 & Colombia $(*)$ & 114 & 42 & 12 \\
223 & Total & 13.442 & 4.931 & 1.473 \\
\hline
\end{tabular}

* Cifras con ganadería.

** Se estimó suponiendo un incremento de área agrícola de 30\% según la SAC, para estimación de cálculos.

Fuente: Sociedad de Agricultores de Colombia (SAC) con base en la Organización de las Naciones Unidas para la Agricultura y la Alimentación (FAO), Ministerio de Agricultura y Desarrollo Rural (MADR), citados porProexport (2010, p. 6).

Es la diversificación de las actividades agropecuarias la que está marcando la iniciativa a la hora de medir el componente económico del sector, en tanto que la producción ya no se destina para fines esencialmente de abastecimiento para el consumo humano, los requerimientos industriales se han hecho sentir en gran proporción, y por ende, las necesidades de fuentes de recursos de crédito y financiación se hacen evidentes, a medida que los demandantes de dichos recursos se encuentran en otra etapa de la actividad, que no necesariamente se manifiesta en mejores opciones económicas para el sector. Ilustra la FAO (2004, p. 14): 
En términos del financiamiento y en una perspectiva de medio y largo plazo el desafio fundamental está en generar un ambiente y políticas públicas que propicien la articulación alrededor del desarrollo de los mercados financieros rurales, del gasto público (social, productivo y en infraestructura), los recursos de ahorro (remesas) de los diversos agentes de la sociedad rural y la expansión de los servicios financieros a través de instituciones financieras sostenibles (bancarias o no bancarias y micro financieras). En general, existe la tendencia a tratar esas dimensiones de la financiación en forma fragmentada y muchas veces en sentidos cuyas resultantes no conduce a la construcción de una institucionalidad que facilite el acceso a mercados en forma sostenible.

El comportamiento cíclico de la actividad productiva del sector agropecuario y su constancia en términos de la proyección a corto plazo y de mediano alcance, puede ir en contra de cualquier expectativa de incubación de recursos provenientes del sector financiero en un lapso mucho más prolongado. La perentoriedad relacionada con la correspondencia entre la actividad productiva como tal y los influjos de dinero que esta exige, y se esperan alcanzar, desvirtúa cualquier interés de focalizar recursos en un plazo de mayor auge, por cuanto estas son actividades que requieren afanar contra el tiempo, y no pueden estar exhortadas a producir bajo directrices financieras de largo trecho. La FAO (2004, p. 3) propone:
El financiamiento a la inversión rural en su acepción más amplia implica encaminar esfuerzos hacia: (a) el mejoramiento del clima o ambiente para el aprovechamiento de oportunidades que se generan en los mercados (de productos, financieros y de servicios); (b) en la gestión de políticas públicas que favorezcan un desarrollo rural incluyente y acceso a los mercados; (c) la utilización eficiente del gasto público; (d) la expansión de los servicios financieros a las áreas rurales, y (e) el aumento en la cooperación financiera internacional al desarrollo.

La hoja de ruta de la actividad financiera del sector está trazada bajo las expectativas que sobre la siembra, la cosecha, la disposición y la entrega del producto conducen a pensar, que independiente de los móviles que pueden crear, de primera mano, aseveraciones que argumentan la inconveniencia de allegar recursos financieros al sector agropecuario, en cuanto a las alternativas financieras que en concreto tiene cada sector y los productores agrarios y agropecuarios, las cuales no pasan de ser evaluaciones financieras exclusivamente, que desconocen las formas de capital e inversión sectorial. Analiza Del Ángel (2005, p. 13-14):

En primer lugar, el financiamiento agropecuario enfrenta riesgos propios, y más complejos que muchas otras actividades. Los riesgos inherentes a la actividad agropecuaria 
más importantes son riesgos de contingencias naturales, riesgos de mercado y riegos de colocación del producto. Por otra parte, la asesoría técnica ayuda a que disminuyan estos riesgos, y a que la rentabilidad de un proyecto se incremente. Los nuevos programas de asesoría gerencial para agro empresas también han sido importantes para controlar estos riesgos.

La postulación de un marco financiero intersectorial en el que el sector agropecuario pueda tener opciones crediticias, hace parte de los trasfondos económicos y crediticios sobre los que deben postularse los mecanismos de financiación del sector. En este frente, la política de apoyo, financiación y subsidios pública, debe alentar igualmente, la reconversión en cuanto a la capacidad financiera real del sector para apalancarse por cuenta propia. Al respecto, el papel que pueda cumplir la disposición sectorial para dicho propósito es otro frente de trabajo por considerar, a efectos de mejorar financieramente al sector.

\section{Réplica Del Ángel (2005, p.17):}

Reconstruir un sistema financiero para el sector agropecuario es un proceso largo y complejo. Queda por responder cómo los intermediarios de fomento podrían crear mecanismos para que este sector pueda tener acceso a los mercados financieros formales y con ello cómo podrían apoyar una inserción exitosa de un

\begin{abstract}
mayor número de productores agropecuarios en esta nueva dinámica de los mercados. Ello considerando que, a diferencia de décadas anteriores, los intermediarios de fomento se encuentran limitados en recursos, y que los mecanismos para apoyar a los productores no generen distorsiones de mercado. En otras palabras, cómo crear un sistema financiero agropecuario que sea económicamente sustentable $\mathrm{y}$ eficiente.
\end{abstract}

Es la productividad la que sostiene las actividades del sector agropecuario, por encima de las mediciones del rendimiento del capital, que tratan de exponer los agremiados bancarios para sostener lo irrelevante que resulta para ellos el disponer recursos a dicho sector. En este sentido, se logra un primer avance respecto a la forma como se miden, para unos y otros, las bondades de la actividad. Mientras que para la banca, la actividad debe responder bajo criterios financieros y luego productivos, para el sector, la productividad es solo un mecanismo para la evaluación financiera y de rentabilidad de la actividad en sí. Comenta Gutiérrez (2004, p. 39):

Los bancos comerciales aparecen como instituciones que pueden contribuir al micro financiamiento agrícola, para lo cual los casos examinados muestran fortalezas: claridad de la misión, focalización en la microempresa, tasas de morosidad muy aceptables, profesionalización de 
la atención, manteniéndose dentro de costos de atención de mercado y con aprendizaje institucional y de recursos humanos en el proceso de crecimiento. Las debilidades se encuentran en que aún no muestran las posibilidades de una masificación de la atención. Aún ha pasado poco tiempo desde que estas instituciones están atendiendo a la microempresa $\mathrm{Al}$ mostrar que hay un nicho de mercado en ese segmento, debieran aparecer nuevos actores en este mercado.

La probabilidad de que el mercado, la producción, la productividad, los rubros económicos y financieros provistos en la actividad agropecuaria permitan recrear estimaciones financieras desde la perspectiva de la banca, debe entenderse bajo otros mecanismos, que incluso no hacen parte del esquema productivo de las empresas dedicadas a dicho sector. Es tarea, entonces, establecer los parámetros y las variables que del sector agropecuario permitirían definir los criterios bancarios, crediticios y financieros para ser atractivos para la banca, que es errática a la hora de entender la composición del mismo o que definitivamente está ajena a las condiciones de capital productivo y generación de recursos para el acceso crediticio frente a la banca tradicional, comercial o financiera. (Ver Figura 1)

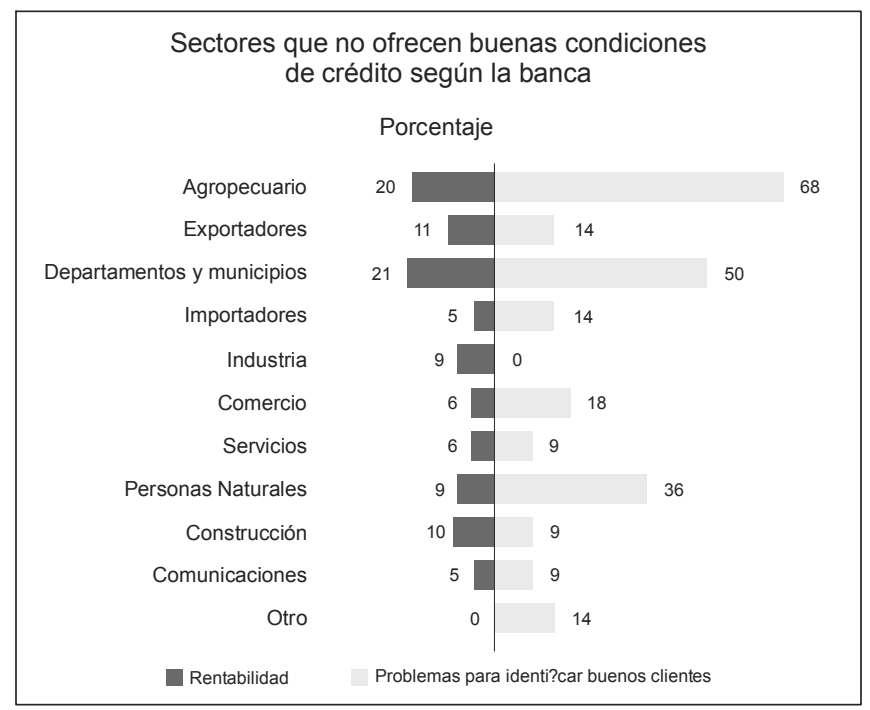

Figura 1. Sectores que no ofrecen buenas condiciones de crédito, según la banca. Fuente: encuesta sobre la situación de crédito en Colombia, diciembre 2012, cálculos del Banco de la República'.

\footnotetext{
Cálculos de acuerdo con los resultados de la encuesta sobre la situación de crédito en Colombia, realizada por el Banco de la República a las diferentes instituciones financieras en marzo 2012: el $30 \%$ de las entidades bancarias consideró el sector agropecuario como el menos rentable y, de forma más crítica, el $90 \%$ de los encuestados argumentó que este es el que más dificultades presenta para identificar clientes potenciales (Castaño, Estrada \& Patiño, 2012, p. 7).
} 
El proceso de revisión sobre el tema consiste en poder establecer los criterios financieros, de rendimiento y rentabilidad desde los cuales pueden extenderse, en principio, los elementos sobre los cuales la banca decide ofertar dinero o recursos del crédito. No obstante, constituye un elemento relevante de rastreo el poder, igualmente, considerar los sectores que representan para la banca intereses por encima de los contemplados bajo la sola disposición o manejo del dinero. Es otra tarea pendiente en el sector, a la hora de consagrar los fundamentos tradicionales del sector agropecuario, bajo la lupa de los intereses de la banca en general. Indican Castaño, Estrada y Patiño (2012, p. 6)

Cuando se considera cómo afectan la rentabilidad y los problemas de información a la hora de identificar buenos clientes, los intermediarios coinciden en que los sectores de industria, servicios, comercio, comunicaciones e importadores son los que ofrecen las mejores condiciones de crédito. Por el contrario, señalan que el sector agropecuario, los departamentos y municipios y los exportadores ofrecen menores condiciones de rentabilidad. Sin embargo, esta percepción ha disminuido entre el segundo y el cuarto trimestre del año y se espera que para los próximos tres meses continúe mejorando. Vale la pena resaltar que los sectores que ofrecen mejor rentabilidad son los mismos que tienen mayor acceso al crédito. La dificultad para identificar buenos clientes por problemas de información respalda la percepción de la baja rentabilidad que se tiene del sector agropecuario: los tres intermediarios financieros afirman que allí es donde más se les dificulta identificar buenos clientes.

En dicho contexto, es importante analizar las condiciones que presentan los diferentes sectores, en este caso del agropecuario, con respecto a las variables mencionadas, pero igualmente, con respecto a las tasas marginales, medias y absolutas de ganancia con sus actividades, que en últimas representan el punto de equilibrio para que las entidades financieras acceder a prestar recursos sin problema. Al determinar la capacidad de transferencia de riesgos o la captura de tasas de manera simultánea entre el sector financiero y real puede hablarse efectivamente de crédito.

\section{ESTIMACIÓN CREDITICIA Y FINANCIERA DE LA BANCA COLOMBIANA SOBRE EL SEC- TOR AGROPECUARIO, DESDE LA SELECCIÓN ADVERSA Y EL RIESGO MORAL}

La banca concibe la relación financiera de cualquier sector con respecto a la relación de activos y patrimonio que los mismos reportan y que constituyen la 
base para evidenciar la rentabilidad básica o fija que puede tener la actividad en virtud de la cantidad y el grueso de recursos involucrados en ellos. Así que, la revisión hecha por este agente económico consiste, en primer lugar, en obedecer a su reconocido acto de no disponer recursos a sectores que carecen respaldo directo en sus principales fuentes de apoyo como las mencionadas, que si bien no son esenciales, sirven de punto de partida para la revisión plena. Destaca Trivelli (2007, p. 39-40):

Se realizó un análisis de las características individuales de algunas entidades que prestan al sector agropecuario/rural según el uso o no de ciertas técnicas en sus tecnologías crediticias (de acuerdo a sus subcomponentes). Las 6 IFR (19\%) que no mencionaron usar los cinco componentes de información (flujos de caja del hogar, negocio, central de riesgo, referencias locales e información del entorno), son entidades de patrimonio y carteras muy pequeñas, con una mayor importancia de la cartera agropecuaria (42\% vs. $36 \%$ ) y con un crédito promedio muy bajo (US\$ 416 de mediana). En cuanto a la exigencia de requisitos al cliente no hay grandes diferencias en las características de las IFR, excepto que las que tienden a exigir más de 3 requisitos, son entidades de mayor tamaño patrimonial y de número de personal, y se orientan más a clientes de mayor monto promedio de crédito, pero no muestran mejores resultados financieros.

La evaluación que se hace en materia de financiación y desembolso de créditos a proyectos del sector agropecuario, obedece a las dimensiones del proyecto y a las condiciones que en el mercado tenga el producto en particular. Es decir, que la banca, apoyada en diferentes argumentos, esgrime la conveniencia de evaluar las solicitudes del crédito bajo el rasero de los datos y números que solo representan un acápite de lo que implica analizar, además de las condiciones intrínsecas de la propuesta agropecuaria, la movilidad del producto, que en realidad no alcanza a cuantificarse fácilmente como se cree. Describen Klein, Meyer, Hannig, Burnett y Fiebig (2001, p.15):

El crédito agrícola entraña altos riesgos de liquidez debido a la estacionalidad de los ingresos de las familias de agricultores. Los excedentes aumentan su capacidad de ahorro y disminuyen su demanda de préstamos después de las cosechas, mientras que el déficit disminuye dicha capacidad y aumenta su demanda de préstamos antes de la plantación de un cultivo. Por lo demás, los prestamistas agrícolas tienen que hacer frente a dificultades específicas cuando la mayoría o todos los prestatarios resultan afectados al mismo tiempo por factores externos. Esta circunstancia se designa como "riesgo covariante", y puede 
menoscabar gravemente la calidad de la cartera de préstamos agrícolas.

El contexto en que se registra el comportamiento bancario, crediticio y financiero del sector cobija una serie de criterios que no hacen parte del tamiz de quien solicita el fondo de crédito. La evaluación que hace la banca obedece a criterios estrictamente financieros que por la discrecionalidad y programación con que se establecen, de tajo saca de las probabilidades cualquier acceso que se tenga por algún adquiriente o sujeto requirente de recursos de apoyo financiero. Es decir, que la banca como tal no busca la financiación del sector sino el de cumplir unas metas de rentabilidad crediticia, superior a la sectorial. A manera de estudio de caso y de ejemplo, comenta Olivares (2004, p.38):

Las entidades financieras formales, además de operar con elevadas tasas de interés (un promedio del $16 \%$ en el sector agrícola en los últimos cinco años, según fuente del Banco Central de Venezuela, año 2005), no comprometen sus recursos en la agricultura campesina, pues ésta se caracteriza entre otras, por su fragmentación, el pequeño tamaño de las unidades de producción, escasas o nulas garantías para ofrecer, indefinición en muchos casos, de la propiedad de la tierra; carencia de sistemas de información, el riesgo implícito de las actividades agropecuarias y los elevados costos de transacción, todos estos factores hacen que la rentabilidad de las líneas de crédito para pequeños productores rurales sea muy inferior a la que se obtiene mediante carteras concentradas en los considerados empresarios agrícolas.

La banca arrastra las expectativas crediticias y financieras hacia metas de redención del capital, que no alcanzan a ser compensadas por actividades en las cuales el componente de reintegros contiene además el acervo de capital y patrimonio involucrado en la actividad. Es decir, mientras que la banca espera una recuperación plena en ambos frentes, a expensas de obtener excedentes adicionales que refrenden el concepto de reproducción del capital, los sectores agropecuarios asumen las condiciones de no recuperación de dichas redenciones, a pesar de que el producto puede arrojar resultados positivos. (Ver Tabla 2). 
Tabla 2. Tipología de los prestamistas rurales

\begin{tabular}{|l|}
\hline 1. Prestamistas formales \\
Banca de desarrollo agrícola \\
Sucursales rurales de bancos comerciales \\
Bancos cooperativos \\
Bancos rurales y bancos comunitarios \\
\hline 2. Prestamistas semiformales \\
Cooperativas de ahorro y crédito \\
Otras cooperativas \\
Bancos semiformales locales o comunitarios \\
ONG \\
\hline 3. Prestamistas informales \\
Parientes y amigos \\
Prestamistas de dinero \\
Asociaciones de ahorro y crédito rotatorio \\
\hline 4. Sistemas crediticios interconectados \\
Proveedores de insumos agrícolas/compradores de cultivos \\
Agroindustrias \\
\hline
\end{tabular}

Fuente: Klein et al. (2001, p.8).

Si bien la cobertura representa una función que pretende abarcar el sistema financiero a la hora de otorgar créditos o acceso a la banca, los mecanismos de evaluación y medición pervierten cualquier intención de hacer llegar los recursos a quienes los necesitan. En este sentido, el sistema se topa con la interacción entre los criterios de selección adversa y riesgo moral, entre los que se destaca que a pesar del profuso interés por entregar más recursos a los diferentes sectores y usuarios, la revisión mecánica que se hace del proceso, hace flaquear este principio, comprobándose de nuevo, que solo pueden hacer uso de los recursos financieros, quienes pueden operar sin necesidad de ellos. Considera Salas (2009, p.10):
Se han identificado los riesgos por atenuar: (i) Riesgo de crédito, derivado de restricciones a créditos formales a corto plazo. (ii) Riesgo de mercado, por la segmentación del mercado y falta de competencia. (iii) Disponibilidad limitada de créditos a mediano y largo plazo. (iv) Escasez de intermediarios financieros operativamente eficientes y sostenibles. (v) Variedad limitada de servicios financieros.

La selección adversa termina ampliando la brecha entre quienes requieren de los recursos provistos en la banca y los que, aún en presencia de ellos, no requieren de dichos flujos para realizar sus actividades. La tendencia se amplia, 
a medida que se evalúan los criterios para acceder a los servicios crediticios y financieros de la banca, la cual en ultimas, tiende a indicar que independiente a los altibajos del sector y a la calidad o condiciones de la actividad por desarrollar, los flujos para reintegrar al sistema financiero contienen unos medidores que ni siquiera alcanzan a contemplarse o mediarse de lleno. Agrega Salas (2009, p. 20):

Las microfinanzas rurales son una nueva forma de abordar el financiamiento rural para las mi pymes en Colombia. Se cambiaron la principal fuente de financiamiento (origen público) por instituciones financieras multilaterales tratando de superar los problemas: gestión de riesgos financieros, altos costos operacionales, baja recuperación, utilización de los recursos por los grupos de más altos ingresos, baja cobertura de las necesidades crediticias de la micro y pequeña empresa.

La reserva que sobre dichas evaluaciones y mediciones hace la banca, constituye precisamente el ejemplo clásico de que, aún bajo cumplimiento de todos los requisitos, la actividad financiera maneja otros criterios, parámetros y variables que no alcanzan a compulsar la intención de quien solicita el crédito. Es importante, que independiente al conocimiento que se tenga de las prácticas y técnicas utilizadas con respecto a criterios, aparentemente desconocidos, el sector agropecuario pueda provocar una revisión mucho más exhaustiva para determinar dichos fundamentos y tomar decisiones al respecto. Establecen Balestri et al. (2001, p.127):

La situación crítica de muchas empresas agropecuarias y la desaparición de algunas de ellas, es producto de la amenaza externa, de un contexto agresivo agravado por las cambiantes políticas económicas del estado, pero también de un componente interno, la escasa formación empresarial del productor. No obstante la conclusión anterior, el modo de decisión predominante basado en la experiencia, agregado a la impresión de que muchas empresas con características similares a las que colapsaron hoy sobreviven, nos generan interrogantes que ameritarían la elaboración de otro estudio. Este podría tener como hipótesis de trabajo que el modo conservador de gerenciamiento de muchos de los empresarios agropecuarios de la zona ha permitido la sobrevivencia en el contexto citado.

El sistema financiero colombiano no cumple a cabalidad la cobertura de las necesidades que se tienen en materia de créditos y financiación de sectores, mal concebidos como riesgosos o vulnerables, para la actividad bancaria. En este 
sentido, es claro que la banca busca reproducir el capital financiero, destacando a su paso el papel especulativo que tiene impregnado dicho capital, y que no responde, en la mayoría de los casos, a las pretensiones del capital productivo. En esencia, la disparidad entre ambos sectores se mide por el tipo de referencia de capital al que hacen hincapié, ajeno uno del otro. Diserta García (2005, p. 23-24):

En Colombia, la colocación de créditos tuvo una caída dramática en 1997 debido a la liquidación de la Caja Agraria, siendo el Fondo de Financiamiento del Sector Agropecuario (FINAGRO) el principal mecanismo de canalización de crédito para los productores. Para pequeños productores, FINAGRO ofrece créditos con una tasa de interés de colocación que no puede exceder la tasa a Depósitos a Términos Fijos (DTF) efectiva anual más $4 \%$, y para medianos y grandes productores, los créditos se colocan a una tasa de interés hasta la DTF efectiva anual más $8 \%$. Los créditos para los productores asociados tienen tasas inferiores a las exigidas en los créditos para productores individuales, llegando la tasa de interés para pequeños productores asociados a la DTF efectiva anual más $2 \%$. Otro elemento esencial de la política de crédito es el Fondo Agropecuario de Garantías que administra FINAGRO, ofrece una garantía complementaria que respalda el valor del capital prestado. El gobierno garantiza mediante este mecanismo entre 50 y $80 \%$ de los créditos. Para lograr coberturas cercanas a $100 \%$ se pueden utilizar contratos de comercialización a través de instrumentos financieros como forwards sobre el producto o buscar la creación de fondos de garantías locales por parte de las entidades territoriales.

La banca, frente al riesgo moral, expresa claramente su aversión a cualquier fórmula tras la cual pueda franquearse la debilidad en el acceso al crédito y las finanzas por parte del sector agropecuario. En este sentido, la búsqueda de mecanismos que superen cualquier asomo de dilación se convierte en una constante para todos aquellos que consideren que el propósito de la banca debe estar dirigido a la articulación de los recursos que posee con la actividad productiva real, y que cualquier asidero fuera de esto, pone a la banca en el papel de reproductora de capital financiero pero nunca de capital productivo. (Ver Tabla 3). 
Mecanismos de financiación y gestión de recursos financieros del sector agropecuario Jahir A. Gutiérrez O. - Nelson E. Castaño - Elimeleth Asprilla M.

Tabla 3. Índice de percepción e importancia de riesgos

\begin{tabular}{|c|c|c|c|}
\hline & Regulados & $\begin{array}{c}\text { No } \\
\text { Regulados }\end{array}$ & Total \\
\hline Riesgos & 0.36 & 0.42 & $\mathbf{0 . 3 9}$ \\
\hline Entorno & 0.25 & 0.25 & 0.25 \\
\hline Alto costo de capital (fondeo) & 0.37 & 0.26 & 0.31 \\
\hline Competencia feroz & 0.23 & 0.31 & 0.28 \\
\hline $\begin{array}{l}\text { Riesgo de tasa de interés (solo para las que } \\
\text { captan ahorros) }\end{array}$ & 0.17 & 0.05 & 0.10 \\
\hline $\begin{array}{l}\text { Riesgo de tipo de cambio (solo para las que } \\
\text { trabajan con moneda extranjera) }\end{array}$ & 0.28 & 0.15 & 0.20 \\
\hline $\begin{array}{l}\text { Riesgo regulatorio legal (dificultades en la } \\
\text { legislación de garantías, sesgos regulatorios) }\end{array}$ & 0.14 & 0.52 & 0.36 \\
\hline Situación macroeconómica desfavorable & 0.32 & 0.24 & 0.28 \\
\hline Agrícolas & 0.64 & 0.71 & 0.68 \\
\hline Reducción de precios de productos agrícolas & 0.49 & 0.66 & 0.59 \\
\hline $\begin{array}{l}\text { Riesgos externos (mal clima, desastres naturales, } \\
\text { crisis macroeconómicas, desorden civil) }\end{array}$ & 0.74 & 0.69 & 0.71 \\
\hline $\begin{array}{l}\text { Interferencia política (leyes de usura, programas } \\
\text { de condonación u/o refinanciación de deudas) }\end{array}$ & 0.68 & 0.78 & 0.74 \\
\hline Clientes & 0.27 & 0.42 & 0.36 \\
\hline Mayoría de clientes no tienen garantías reales & 0.42 & 0.65 & 0.56 \\
\hline $\begin{array}{l}\text { Mayoría de clientes no tienen oportunidades } \\
\text { para hacer inversiones rentables }\end{array}$ & 0.18 & 0.20 & 0.19 \\
\hline Incumplimiento de contratos & 0.29 & 0.40 & 0.36 \\
\hline $\begin{array}{l}\text { Falta de información de capacidad de pago de } \\
\text { clientes potenciales }\end{array}$ & 0.20 & 0.41 & 0.33 \\
\hline Gestión & 0.29 & 0.28 & 0.28 \\
\hline Falta de liquidez & 0.23 & 0.29 & 0.27 \\
\hline $\begin{array}{l}\text { Riesgo operacional fraude del personal/fallas } \\
\text { de equipos) }\end{array}$ & 0.42 & 0.27 & 0.33 \\
\hline $\begin{array}{l}\text { Controles internos deficientes y sistemas de } \\
\text { contabilidad débiles }\end{array}$ & 0.22 & 0.27 & 0.25 \\
\hline
\end{tabular}

Fuente: Encuesta del BID a las instituciones financieras rurales (2006), citado por Trivelli (2007, p. 42)

Es importante que se comprenda la capacidad que tiene la banca para sortear la posición descreída que ha tomado frente a la capacidad y condiciones que puede arrojar el sector agropecuario. El no abrir a medio o largo plazo un escenario claro y concreto sobre el cual puedan actuar ambos frentes, banca y sector agropecuario, terminará por afectar incluso la actividad financiera a largo 
plazo, por el interés que ha venido despertando en diferentes frentes la posibilidad de invertir en diversos proyectos convergentes a la actividad agropecuaria en el mundo, tras los cuales, la banca puede terminar aislada. Ejemplarizan Urdaneta y Garnica (2012, p. 44-45):

Frente a la definición de la modalidad de crédito más apropiada para el proyecto, se encontraron opiniones diferentes entre el Banco Agrario y Finagro. De acuerdo con consultas realizadas con asesores de Finagro, en la oficina central en Bogotá, era posible acceder a un crédito asociativo por organización y que las inversiones colectivas, como centro de acopio nuevo y equipos, podían quedar en cabeza del resguardo indígena, ya que no existía ninguna limitante por ser de reciente creación. El Gerente Regional del Banco Agrario en Cali dio el mismo concepto por escrito. Sin embargo, los funcionarios del Banco Agrario en Popayán manifestaron que estas organizaciones no cumplían con los requisitos, por ser recién creadas y/ o por no contar con los estados financieros requeridos. Más allá de esta información básica, no fueron claros los criterios técnicos que se tuvieron en cuenta para calificar a las organizaciones presentadas, ya que no se encontraron lineamientos sobre estos procesos de evaluación en los manuales, al estilo de un esquema de puntaje y calificación con base en flujos financieros u otros aspectos.

La explicación sobre el riesgo moral, a efectos de entender el comportamiento de la banca, radica precisamente en la posibilidad de orientar los elementos que se requieren para que la banca tenga asomo en las actividades del sector agropecuario, y que si bien este último en principio no tiene capacidad de reproducir capital financiero, podría ofrecer otros elementos importantes para el ascenso, manutención y preservación de las expectativas sembradas en un sector al que le falta incorporarse efectivamente a las actividades reales, evaluando desde el capital financiero, productivo u otros. Plantea Romy (2005, p. 33):

Los grandes desafíos de la globalización hacen no sólo necesaria sino imperiosa la tarea de reconstruir la banca de desarrollo en nuestra región. Una banca de desarrollo eficiente y transparente, orientado a crear segmentos del mercado financiero que no se desarrollan automáticamente, puede no sólo jugar un papel esencial en el mundo global, sino, además convertirse en poderoso motor de desarrollo financiero privado.

Es menester disipar las dudas, incongruencias y malinterpretaciones relacionadas con la baja o poca capacidad de financiación del sector agropecuario colombiano. Al respecto, 
las condiciones de accesibilidad y adquisición de productos financieros puede solventarse en la medida en que las expectativas de los sectores involucrados terminen por estimar los puntos de convergencia que con respecto al capital ponen a uno y otro a tomar distancia respecto a la capacidad y entereza que tienen para ser sujetos del crédito y de desestimar la inconveniencia de acercar recursos a este sector. (Ver Figura 2).

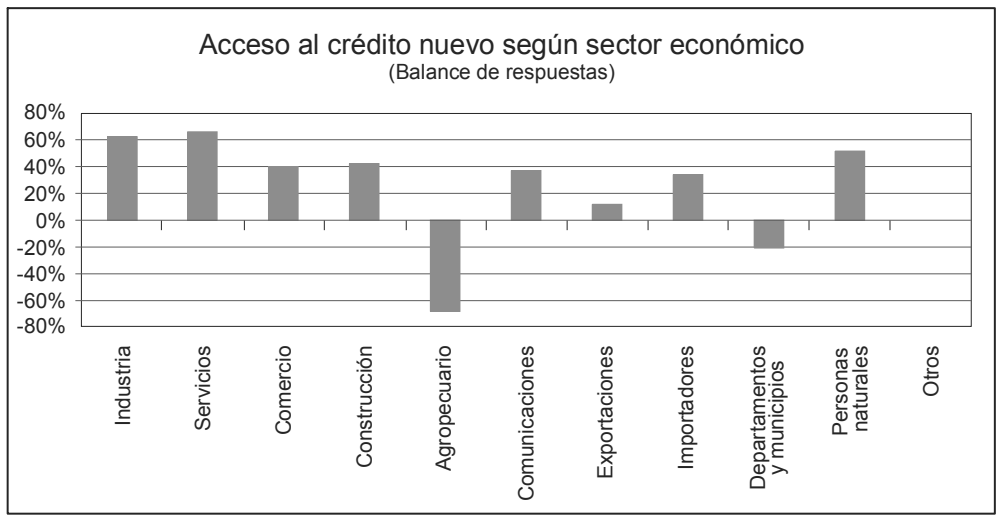

Figura 2. Acceso al crédito por sectores

Fuente: encuesta Banco de la República (2012, anexo, p. 16). Encuesta sobre la situación de crédito en Colombia, diciembre 2012, citado por Castaño et al. (2012, p. 16) ${ }^{2}$.

La disposición para con los sectores referenciados en cuanto al acceso al crédito o la renovación del proceso crediticio que cada uno de ellos percibe, hace parte del análisis que debe corroborarse con respecto a la probabilidad de que no solo la tasa de ganancia genere algún tipo de cambio positivo para que la banca estime la conveniencia de ofertar recursos, y por parte del sector agropecuario, la posibilidad de que en un orden recíproco las tasas de ganancia en equilibrio de ambos sectores, además de ser sostenibles, puedan habilitar la continuidad de los recursos del crédito, aun en momentos difíciles para la sostenibilidad de la misma.

2 Durante el cuarto trimestre de 2012, el acceso al crédito de los diferentes sectores ha presentado un comportamiento mixto. Los bancos indican que se ha dado una disminución en la mayoría de los sectores: en particular se observa que la industria y los servicios (los principales sectores para este grupo de intermediarios), junto con los departamentos y municipios, mostraron importantes reducciones. Por su parte, las CFC y las cooperativas consideran que en general el acceso al crédito se ha incrementado para la mayoría de los sectores, especialmente para la industria y los servicios. Vale la pena resaltar que los tres grupos de intermediarios consideran que el sector agropecuario continúa siendo el que presenta mayores restricciones, y en el último trimestre del año empeoró su acceso al crédito en comparación con trimestres anteriores. 
CALIDAD Y CONDICIONES TÉCNICAS DEL SECTOR AGROPECUARIO COMO SUJETO ACTIVO DEL CRÉDITO DE LA BANCA EN COLOMBIA

La orientación recibida por el sector agropecuario en materia de instrumentos, elementos y estructura dirigida al involucramiento de este en las ofertas bancarias, crediticias y financieras, no ha pasado por una amplia consideración, que conforme a criterios de juicio, pueda ofrecer una idea clara al respecto. Así, la característica más importante vinculada al otorgamiento de liquidez ha corrido por las líneas de crédito, desarrollo y fomento provistas por el Estado, de la mano con diferentes entidades del orden oficial y entidades financieras multilaterales, que han terminado por afincarse en banca de segundo piso. Caracteriza Weisburd (2002, p. 25):

En este contexto, ante la falta de Crédito, es necesario buscar medios de financiamiento alternativo. Las Operaciones de Canje por Productos Agropecuarios tradicionalmente limitadas al "Canje de Insumos" adquieren una importancia significativa. A partir de la salida de la Convertibilidad, este tipo de operaciones se ha generalizado hasta el punto de poder adquirir maquinarias, automotores, inmuebles, etc. mediante este tipo de operatoria debido fundamentalmente al hecho de que la producción agraria tiene precio internacional.
Es evidente que la disposición de recursos del crédito es impulsada por los capitales que desde diferentes departamentos nacionales, entidades públicas descentralizadas y ministerios terminan siendo dirigidos a la proyección de productivos puntuales o rubros específicos en actividades de interés nacional. Es el Estado el que ha pedido apoyo y complementariedad a las entidades privadas para contribuir al acceso, disposición y entrega de dichos recursos, debido a la propia estructura que tienen estos y su fuerza promotora para transformar productos bancarios en iniciativas exitosas en el sistema financiero. Explica Sánchez (1998, p. 8):

Un porcentaje alto de las unidades de producción agropecuaria en el país, desarrollan su actividad agraria como única alternativa y no como un propósito claro de desarrollar una actividad que además de lo productivo, exista lo comercial y lo financiero; predominan las estructuras económicas que corresponden a lo que se denominan genéricamente organizaciones sociales, sin que ellas existan las características fundamentales de la empresa agraria, como son : declaración de un propósito o misión y definición de objetivos relacionados con utilidades, rentabilidad y crecimiento, logrados mediante la realización de actividades productivas, comerciales, económicas y financieras.

La banca privada ha actuado sigilosamente a la hora de auspiciar en su naturaleza la entrada de líneas de 
crédito o fomento creadas por el Estado. En este sentido, se entiende que la perspectiva de la banca privada no está propiamente en fortalecer ningún sector, sino en aprovechar los impulsos que ostentan algunas actividades de manera puntual, y que representan para ella, la posibilidad de solventar las necesidades y responsabilidades que implica el manejar capital financiero por encima del capital productivo. En términos generales, cuesta mucho señalar a la banca como fuente de capital de trabajo. Expresa Dieter (2000, p. 45):

¿Qué futuro tienen los bancos de desarrollo agrícola, en muchos casos no rentables y considerados a menudo los elefantes blancos del financiamiento para el desarrollo? Estas instituciones fueron establecidas hace 20 o 30 años, con el fin de prestar servicios financieros, principalmente crédito, a tasas de interés subsidiadas, a clientes considerados insolventes por los bancos comerciales. Son en gran medida de propiedad estatal y los financian el propio Estado y las entidades internacionales donantes. En general, se han centrado en el otorgamiento de crédito, más que en la aceptación de depósitos, lo cual ha ido en detrimento de su capacidad de auto sustentación y de su viabilidad.

El funcionamiento de la banca está a expensas de la movilidad de los indicadores económicos y financieros, que comúnmente responden a las alteraciones y variabilidad de múltiples mercados, y cuyo espacio para la especulación es una constante. La banca como tal, no es cautelosa en materia de inversiones o por lo menos sobre los que con cargo a sus propias decisiones asume, por cuanto, en muchas ocasiones, se espera que la propia circulación de dinero no solo reintegre un remanente importante sino que traduzca la movilidad de este en un mayor número de recursos por fuera del ciclo productivo corriente y normal. De nuevo contextualiza Dieter (2000, p. 47):

En los años noventa en diversos foros internacionales surgió un consenso a favor de la promoción de modalidades viables de financiamiento bancario rural, inclusive a través del otorgamiento de crédito, mecanismos de ahorro y otros servicios financieros para mujeres y hombres pobres. La reciente crisis financiera asiática ha puesto de manifiesto también la necesidad de una vigilancia y regulación más estrechas de las entidades financieras, incluidos los bancos de desarrollo agrícola y las instituciones de micro financiamiento.

El acomodamiento del sector agropecuario tarda a la ahora de acoplar las movilidades del sistema financiero a sus expectativas. Mientras que la banca arrastra consigo un cúmulo de sobresaltos que deben ser internalizados en sus acciones y decisiones, el sector 
agropecuario no alcanza a estimar la tendencia que pueden tomar las decisiones en materia de crédito o financiación. Esta situación sirve de base para explicar porqué para el sector bancario y financiero la velocidad con que atiende sus actividades y negocios de manera geométrica no puede ser alcanzada por las actividades reales en mención. Referencia Montoya (2012, p.19):

Los empresarios de este sector consideran que los puntos más importantes que se deben mejorar para aumentar la producción son los costos y disponibilidad de insumos, transporte disponibilidad de crédito y el clima. Asimismo, el grueso de su inversión agropecuaria, que en los últimos 3 años ha perdido fuerza, lo destinan a maquinaria, adecuación de tierras y obras de infraestructura.

La velocidad con que se forjan las expectativas en uno $\mathrm{u}$ otro sector determina la probabilidad de acercamiento o distanciamiento que entre los dos se establece. La banca solo asoma en los campos del sector agropecuario cuando existe "plena garantía" de que el recurso por explotar alcanza igual o superior dinamismo al resto de sectores de la economía, entre los que, claro está, debe contarse por sí mismo. Al respecto, la estructura dinámica que puede tener la producción en este sector, tiende a ser elástica con sectores de baja remuneración e inelástica para sectores con alta remuneración, pero baja perdurabilidad de sus ciclos. Propone Lafaurie (2011, p. 1):

La renuncia de Juan Carlos Botero a la presidencia de la Bolsa Mercantil de Colombia -anterior Bolsa Nacional Agropecuaria-, es el preámbulo de la urgente restructuración que requiere la entidad, de cara al anhelo de consolidar un mercado de capitales para el campo. A decir verdad, han sido 32 años de intentos, que terminaron por reducir los escasos instrumentos de negociación y quebrar la Cámara de Riesgo Central de la BMC. Noticia que sepulta cualquier posibilidad para los mercados de futuros y opciones de productos agropecuarios $\mathrm{y}$, con ello, los beneficios en materia de formación de precios y financiamiento alternativo para el sector.

El comparativo de datos económicos establece el grado de inconsistencia que existe a la hora de evidenciar los criterios que utiliza la banca para medir las condiciones crediticias y financieras. Es claro que la reciprocidad no hace parte de la complementariedad que podrían tener uno y otro sector, que, sin embargo, tienen la posibilidad de ponerse de acuerdo en la medida en que puedan negociar variables tan concretas como las tasas de interés referidas a los desembolsos y los montos en el tiempo a pagar; escenario que convoca de manera permanente a la revisión de la educación financiera y la bancarización. Expresan Balcázar, Vargas y Orozco (1998, p. 6): 
La información disponible en Colombia sólo permite identificar una parte de las relaciones del agro con otros sectores, y es la que se refiere a la agroindustria, o industrias de procesamiento y transformación de bienes agropecuarios (enlaces hacia adelante). Las industrias que producen insumos y los sectores que proveen servicios para la producción agropecuaria (enlaces hacia atrás) no se pueden desagregar de los datos disponibles sobre el PIB nacional. Tampoco se pueden medir los enlaces con otros sectores como el de comercio y servicios, para sólo señalar algunos, que en la actualidad están entrelazados con el sector agropecuario.

La banca tiene en su haber la necesidad de limitar o responder ante los requerimientos que se le hacen respecto a la posibilidad de crear, disponer y entregar recursos a los sectores que requieren de liquidez. En apariencia, es un llamado más a la revisión de la composición anquilosada y orgánica que ha hecho carrera en las instituciones bancarias en general, respecto a la manera como se acepta y comprende que deben llegar los recursos financieros a diferentes usuarios. Es la banca la que no ha mostrado avances significativos, $y$ que por ende, la velocidad que ostenta es igualmente dilapidadora de su hacer. Plantean Niño y Llorente (2009, p. 3):

Al respecto, a la luz de objetivos de sostenibilidad del sector financiero, hay que recalcar que la responsabilidad de esta actividad de intermediación no puede reducirse meramente al nivel económico. Las políticas y servicios adoptados por este sistema tienen un gran impacto sobre la economía y bienestar de un país, y por lo tanto, debe estudiarse hasta qué punto y de qué manera su responsabilidad debe trascender los intereses particulares, y debe comprometerse con su misión social encaminada hacia el bien común (Niño \& Llorente, 2009).

En este sentido, la asociatividad debe ser el baluarte que acompañe en adelante la interacción de las entidades financieras. En ella descansa la posibilidad de las entidades bancarias de materializar con hechos la cobertura y bancarización sobre la cual pretende desplegar sus acciones. El paso de la banca, del crédito a la financiación y de esta última a la asociación bancaria con diferentes actividades, debe ser parte del balance económico y social que espera obtener ella de su gestión. La inquietud estriba en como respaldar el concepto de asociatividad para una actividad catalogada de individualista. Argumenta Marulanda (2006, p. 51):

La presencia única del Banco Agrario en los municipios de menor tamaño no ha permitido mejorar el acceso de la población de menores recursos o de las micro y pequeñas empresas de estos lugares. Esta institución le ha concedido preferencia al crédito agropecuario, 
movilizando principalmente recursos de FINAGRO, el banco de segundo piso para el sector agropecuario, sin promover el crédito a otros segmentos de la población ni la movilización de ahorros del público, lo cual ha sido corroborado en algunos estudios de carácter cualitativo realizados en el país

La aparición de la gestión financiera no corresponde al cúmulo de herramientas para determinar los componentes representativos que indican la sanidad o el riesgo en el que pueda estar la actividad. La gestión financiera radica en la recomposición del papel que cumple la banca con respecto a sectores excluidos por parámetros técnicos $\mathrm{y}$ modelos acondicionados para que redunden en espirales y promedios que alejan, incluso en el tiempo, las expectativas de crecientes ganancias que siempre aspiran a obtener. De allí, que es importante acusar dicha asociatividad con modelos de negociación financiera. Da cuenta Proexport (2010, p. 13):

El sector agropecuario colombiano cuenta hoy con: - Un banco agropecuario de primer piso, Banco Agrario de Colombia, con activos cercanos a US\$12 mil millones. $\bullet$ Un fondo de financiación agropecuaria, FINAGRO, con activos por cerca de US\$ 2,4 mil millones. - Una amplia gama de líneas de financiamiento: Tabla 4.

Tabla 4. Líneas de financiación para el sector agropecuario

\begin{tabular}{|l|l|}
\hline Capital de trabajo & Producción \\
& Sostenimiento \\
& Comercialización \\
\hline Inversión & Siembras \\
& Compra de animales \\
& Maquinaria y equipo \\
& Infraestructura \\
& Comercialización \\
& Servicios de apoyo \\
\hline
\end{tabular}

Fuente: Finagro

La modelación de negocios financieros derivados de la asociación bancaria entre el sector agropecuario y bancario, responde al papel básico que cualquier inyector económico realiza en otros sectores. La banca no puede abstraerse del comportamiento o conducta de los sectores que de manera directa o complementaria hacen parte de toda la estructura económica. Al contrario, es la 
banca la llamada a liderar la correlación entre los parámetros indelebles de la información financiera con los escenarios en que se plantea que el sector podría o no responder, y que por ello, habría que reconsiderar diversos temas. Indica Ramírez (2010, p. 35):

Cuando se adquiere un Crédito Agropecuario, la entidad bancaria requiere garantías para respaldar las obligaciones. "Bajo la Ley 21 de 1985 fue creado el Fondo Agropecuario de Garantías que tiene por objeto respaldar los créditos otorgados por el fondo financiero agropecuario a los pequeños usuarios y a las empresas asociativas que no pueden ofrecer las garantías exigidas normalmente por los intermediarios financieros". "En 1999 bajo el decreto 1447 del Ministerio de Agricultura y Desarrollo Rural amplió la cobertura a cualquier productor agropecuario e igualmente ratificó que no podrán ser beneficiarios del FAG las personas que tengan préstamos no agropecuarios con el sector financiero bajo cobro judicial o mal calificados". Desde ese momento y con este programa de Gobierno FINAGRO ha logrado un crecimiento en los desembolsos.

El fungir como acreedor o prestamista se encuentra fuera de vigencia, debido precisamente a la necesidad de que se entienda que cuando la banca dirige sus expectativas sobre la base del comportamiento especulativo, reduce la posibilidad de acceso a los sectores reales que efectivamente hacen posible el flujo de dinero. Es en ese momento, cuando la banca gire en torno a la medida de la economía real, el momento en que pueda indicarse que la banca ha dejado las fórmulas robustas de medición por las de ponderación de los hechos reales, sobre las cuales el interés por el capital de trabajo supera al especulativo. Comenta Montoya (2012, p. 20):

El año pasado la cartera encabezada por el ministro de Agricultura, Juan Camilo Restrepo, dio a conocer el Programa de Desarrollo Rural con Equidad (DRE) el que pretende impulsar a los pequeños y medianos agricultores de todo el país. Inicialmente, fue planteado con un presupuesto de $\$ 500.000$ millones en el 2011, pero ahora el Gobierno espera disponer de un $26 \%$ más para el 2013 para así llegar a los $\$ 630.000$ millones. En concreto, el DRE se divide en 4 líneas principales: 1.Línea especial de crédito que financia productos básicos como arroz, cebada, avena, frijol, arveja, hortalizas, frutas, soya, plátano, yuca, papa y maíz. 2. Incentivos a la capitalización rural (ICR), que ayuda a los pequeños y medianos productores individuales y asociados, donde la participación de los pequeños sea mínimo el $60 \%$ del área sembrada. 3. Incentivos a Proyectos de Riego y Drenaje, instrumento no crediticio a los 
productores agropecuarios, 4 . Incentivo a la asistencia técnica.

Lo fundamental es poder trasladar el interés de trabajar mancomunadamente, ampliando los canales y mecanismos de acceso a la financiación, y eso se logra, a medida que se asume el papel de la reconversión y transformación del aparato financiero, allanando escenarios sobre los cuales poder estimular el acceso a la banca y el crédito, como por ejemplo, la definición de una política macro crediticia y financiera, creíble desde la lógica de la política económica estatal y la propia pública sectorial. En este sentido, la tarea está toda por hacer debido a la parsimonia y papel errático que propiamente ha cobijado el quehacer de los administradores y gestores de recursos, y que ha confluido para que se estimen otras fuentes de financiación distintas a ellas.

\section{CONCLUSIONES}

El sector agropecuario nacional, de la mano con el gobierno, debe generar una política nacional de revisión frente a las condiciones bancarias, crediticias y financieras sobre las que se solventa. La posición, un tanto descuidada y de poco interés, campea en los principales gremios pertenecientes a la actividad del campo, que ante posiciones tan concretas de no ser sujetos de crédito, hacen poco por superar dicho señalamiento, dejando al Estado solo a la hora de acusar las bondades y perfiles que debe tener la banca moderna para canalizar recursos a dichas actividades, cuya expectativa de retorno de capital debe tener algún atractivo.

La banca, en general, está sometida a la mediación que provoca la interpretación de modelos y a la derivación de análisis consecuentes con las programaciones crediticias o financieras que haga. No obstante, es de observar que la trayectoria alcanzada por dicho sector en el tiempo está en juego, si aún continua reservando sus recursos fuera del entorno rural, en donde yace una forma diferente de entender el oficio y derrame de recursos a la par de los procesos de acumulación que puede generar si piensa en colectivo y no en individuos.

Es trascendental para el establecimiento de los flujos de dinero hacia actividades, aparentemente no rentables, que se incentive a los mismos generadores $\mathrm{y}$ promotores de crédito y servicios financieros para que recreen mejores posibilidades de acceso. Por ahora, la atomización característica de la banca colombiana, termina aun por arrojarla a actividades de especulación de manera completa, razón por demás para que, finalmente, se crea que los bancos terminen convertidos en holdings financieros con más impacto en la bolsa que en la propia actividad económica, factor que puede restarle captar recursos.

El entorno diagnóstico sobre el que se han desarrollado los últimos estudios, tiene la tendencia de reiterar las dificultades que 
tienen los sectores para acceder a los mecanismos de financiación o las ofertas financieras previstas. Lo importante del presente análisis, es que pueda advertirse sobre la probabilidad de que el sector agropecuario, entre otros, pueda tener unos servicios financieros que contribuyan a su quehacer, más allá de la presencia o entidades, y de otro lado, para que puedan ser establecidos los canales de acceso a los créditos entre diferentes agentes hacia el sector agropecuario.

El sector financiero colombiano, en conjunto con sus principales agremiaciones, debe entender que el ciclo económico de los sectores productivos es una realidad que igualmente debe incubarse en los análisis y precisiones que hacen de los sectores. Es prioridad para este sector, incorporar en sus previsiones las alteraciones y contingencias que perciben los sectores que consideran altamente riesgosos o no atractivos para los créditos, por cuanto, en ninguna parte del mundo se asegura que la banca $u$ otros puedan garantizar beneficios crecientes, por fuera o dentro de los ciclos económicos directos o indirectos.

\section{AGRADECIMIENTOS}

A la joven investigadora, Heidy Yulieth Ospina Galvis, por el acompañamiento en el proyecto de investigación "Canales y mecanismos de acceso a la financiación y fondeo préstamos a sectores no aptos para el sistema financiero colombiano. El caso del sector agrícola, construcción, exportadores, municipios y pymes", en la búsqueda de información y fuentes. La joven investigadora es egresada de la Facultad de Administración Financiera (2012), de la Institución Universitaria Tecnológico de Antioquia, perteneciente al Grupo Observatorio Público de la Institución Universitaria Tecnológico de Antioquia.

\section{Referencias}

Balcázar, V., Vargas, A. \& Orozco, A. (1998). Del proteccionismo a la apertura ¿el camino a la modernización agropecuaria? Centro de Estudios Ganaderos y Agrícolas CEGA. Misión Rural, 1-106.

Balestri, L.A., Ferrán, A., Giorgis, A., Saravia, C.D., Larrea, A.T., Castaldo, A., Poma, K. \& Pariani, A. (2001). La toma de decisiones en las empresas agropecuarias del norte de la provincia de La Pampa. Argentina: Facultad de Ciencias Veterinarias, Universidad Nacional de La Pampa.

Banco Agrario de Colombia -Banagrario-. (2006, dic.). Capitulo 4. Banca de desarrollo para el agro: experiencias en curso en América Latina (p. 46- 62). S.1.: Banagrario. 
Castaño, J., Estrada, D. \& Patiño, M. A. (2012). Reporte de la situación del crédito en Colombia. Bogotá: Banco de la República.

Congreso de la República. (1985, 8 de enero). Ley 21, por la cual se crea el Fondo de Garantías -FAG-Fondo para el Financiamiento del Sector Agropecuario -FINAGRO-.

Del Ángel, M. G. A. (2005). Transformaciones del crédito agropecuario. El caso de FIRA en perspectiva histórica. Documento de Trabajo $\mathrm{N}^{\circ} 320$. México: Centro de Investigación y Docencia Económicas CIDE, División de Economía.

Dieter, S. (2000, junio). Bancos de desarrollo agrícola ¿Cerrarlos o reformarlos? Finanzas \& Desarrollo.

FAO (2004, abril). Mesa redonda: Financiamiento para el desarrollo agrícola y rural. En $28 a$ Conferencia Regional para América Latina y el Caribe. Ciudad de Guatemala.

García, A. (2005). Instrumentos de apoyo al sector agropecuario y competencia en la comunidad andina. Informe técnico en el marco del proyecto COMPETENCIA. Documentos Informativos, 1-74.

Gutiérrez, A. (2004, dic.). Microfinanzas rurales: experiencias y lecciones para América Latina., diciembre del 2004. Serie Financiamiento del Desarrollo 149. Santiago de Chile: Unidad de Estudios Especiales. Secretaría Ejecutiva Santiago de Chile.

Klein, B., Meyer, R., Hannig, A, Burnett, J. \& Fiebig, M(2001). Mejores prácticas del financiamiento agrícola. Replanteamiento de las finanzas agrícolas. Organización de las Naciones Unidas para la Agricultura y la Alimentación -FAO-, Deutsche Gesellschaft für Technische Zusammenarbeit-GTZ-, (3), 1-102.

Lafaurie, R.J. F. (2011). ¿Qué pasa con la BMC? FEDEGAN, 1-2.

La Nota Económica. (2012, sept. $2^{\mathrm{a}}$ quincena). Las TIC cultivan los frutos para la agricultura. Universo TIC, 24-28.

Marulanda, B. (2006). Una nueva política para un mayor acceso a los servicios financieros en Colombia. Secretaría General Iberoamericana. La extensión del crédito y los servicios financieros. Obstáculos, propuestas y buenas prácticas. Encuentro Empresarial. XV Cumbre Iberoamericana en el seno de la iniciativa La extensión del crédito y los servicios financieros. Madrid, España.

Ministerio de Agricultura y Desarrollo Rural. (1999, 3 de agosto). Decreto 1447, por el cual se amplía la cobertura del Fondo de Garantías -FAG- Fondo para al Financiamiento del Sector Agropecuario FINAGRO.

Montoya, A. (2012, octubre). Formación y salto competitivo. PyMEs de talla mundial. La Nota Económica, 17-22. 
Mora, C. \& Serna, R. (2010). Las entidades bancarias en Colombia consecuencia de un movimiento constante del sector bancario. Revista MBA EAFIT, 32-53.

Niño, D. P. \& Llorente, B. (2009, 24 y 25 de septiembre). Equidad y eficiencia en la banca colombiana: evidencia del aporte de las prácticas de responsabilidad social empresarial. En IX Congreso latinoamericano ALENE.

Olivares, R. (2004). El financiamiento informal en el sector agrícola. Visión Gerencial, 3(2), 37-45.

Proexport Colombia (2010). Invierta en Colombia. Sector agroindustrial colombiano, 1 (1), 1-17.

Ramírez, B. D. (2010). Estudio descriptivo del redescuento como mecanismo de fomento financiero para el sector agroindustrial en Colombia, caso Fondo Financiero Agropecuario FINAGRO. Tesis no publicada, Facultad de Administración, Finanzas y Ciencias Económicas. Bogotá: Universidad EAN.

Romy, C. A. (2005, septiembre). La banca de desarrollo en América Latina y el Caribe. En Proyecto CEPAL/BID El reto de acelerar el crecimiento en América Latina y el Caribe (BID 03/ 098).(p. 1-44). Serie Financiamiento del desarrollo 157. Santiago de Chile: CEPAL, BID.

Salas, G. (2009, 10-13 de agosto). Política de financiamiento rural colombiano 1990-2009. Crédito agropecuario. En SEPIA XIII Mesa Especial Finanzas Rurales. Cusco.

Sánchez, Z. (1998). Análisis financiero empresarial. Aplicación al sector agropecuario. Bogotá: Universidad Nacional de Colombia.

Trivelli, C. (2007). Riesgos y portafolios agropecuarios: lecciones desde la experiencia deinstituciones financieras de América Latina. En C. Trivelli \&A. Tarazona. (Documento de Trabajo, 151. Serie Economía, 46). Lima: IEP.

Urdaneta, M. \& Garnica, R. (2012). Evaluación de las condiciones de acceso a créditos agropecuarios para pequeños productores. Bogotá: Fundación Alpina con el apoyo de OXFAM.

Weisburd, P. (2002). Medios alternativos de financiamiento agropecuario. Programa de Formación. Recuperado de www.cursos.bcr.com.ar 